\title{
The "Learning Through Play" project. Importance of interdisciplinary work among children born prematurely and their family groups in an area of high socio-environmental risk
}

\author{
Flor L. Tobar, M.D. ${ }^{a}$ and Manuel J. Lencina, B.S. ${ }^{b}$
}

\begin{abstract}
Several socio-environmental risk factors causea large number of children born prematurely, and without neurological disorders, to have low scores in their development, particularly in the cognitive and socio-emotional skills areas, thus evidencing a potential future risk. Strengthening bonds with the family and caregivers is critical for their adequate development.

This article reports on the experience of an interdisciplinary team from Hospital Eva Perón de Tucumán, who designed a program called "Learning Through Play"for the promotion of child development and aimed at parents of preterminfants seen at the Follow-up Outpatient Clinic and the Department of SocialServices, with the collaboration of the Department of Nutrition. Key words: Preterm newborn, environmental risk, intervention, bond, cognition.
\end{abstract}

http: / / dx.doi.org/10.5546/aap.2017.eng.588

a. Preterm Follow-up Outpatient Clinic, Unit of Neonatology Management, Hospital Eva Perón de Tucumán, Banda del Río Salí, province of Tucumán, Argentina.

b. Department of Social Services, Unit of Patient Management, Hospital Eva Perón de Tucumán, Banda del Río Salí, province of Tucumán, Argentina.

E-mail address:

Flor L. Tobar, M.D.:

florltobar@gmail.com

Funding:

None.

Conflict of interest: None.

Received: 9-30-2016 Accepted: 5-10-2017
To cite: Tobar FL, Lencina MJ. The "Learning Through Play" project. Importance of interdisciplinary work among children born prematurely and their family groups in an area of high socio-environmental risk. Arch Argent Pediatr 2017;115(6):588-594.

\section{INTRODUCTION}

Indicators such as poverty, family diseases, socio-emotional problems, violence, battering, and family abuse causea large number of children born prematurely, and without evidence of neurological disorders, to fall behind the pace of development expected for their age, thus increasing their vulnerability and affecting their quality of life and future possibilities. ${ }^{1}$ Such alterations, which are usually moderate, are reflected in a lower academic performance and, moreover, a poorer social adaptation compared to their peers..$^{2,3}$ In general, children with an evident motor disorder have access to intervention centers. However, the rest of these children, as in this case, have no access to a public system capable of providing support and education. Thus, these children are affected during the critical first two years of their development, which is a period of high vulnerability and importance for the anchorage of the bases of their developmental structures, which are fundamental for their future comprehensive involvement in society, leaving them at an evident potential risk. ${ }^{4-6}$

These difficulties were observed among children in this age group who were born prematurely and seen at the Follow-up Outpatient Clinic and the Department of Social Services of Hospital Eva Perón de Tucumán. Using the Child Learning and Development Test (test de aprendizaje y desarrollo infantil, TADI), ${ }^{7}$ overall scores were normal but partially lower in the socio-emotional skills and cognition areas.

Looking for a common cause, it was observed that their families failed to spend time playing with them or to provide them with an adequate positive socialization. In view of the need to conduct an intervention as early and timely as possible in this critical period, ${ }^{8-10}$ a tool was proposed for the implementation of therapy through experiences with parents and their families: experiential workshops for the promotion of child development under the "Learning Through Play" project. Thus, through play, their lives'realities were described and different values, which are detailed below, were analyzed, for example that of being a person. These values were chosen because they are principles that guide our behavior based on the goal of becoming a good person. 
The project is about describing the experience, its impact in the family environment, and the improvement of scores in the most affected areas. It is worth noting that this was the only provincial hospital conducting these workshops on its own, entirely developed and conducted through the interaction between the Follow-up Outpatient Clinic and the Department of Social Services, and in collaboration with the Department of Nutrition.

\section{PROGRAM OBJECTIVE}

To enable parents to find their own tools based on their personal playing experience and, through such experience, encourage and favor interaction with their children based on a strengthened bond and their work with values (multiple module model). ${ }^{11}$

\section{GEOGRAPHIC LOCATION, POPULATION, AND SOCIAL RISK SITUATION}

The Hospital Eva Perón is located in Banda del Río Salí, in the province of Tucumán, adjacent to the capital city. It is a member of the East Programmatic Area and is made up of a large population at socio-environmental risk, which predisposes and responds to risk indicators for preterm births, including socio-environmental factors, ${ }^{12-14}$ and corresponds mostly to the towns of Alderetes and La Banda. In addition to providing an excellent quality service, among other things, it is characterized for focusing health care based on community needs through active listening and in respect of the population's rights and culture. The Follow-up Program receives preterm newborn infants with a birth weight of $1500 \mathrm{~g}$ or more.

According to the Neonatal Follow-Up Social Service, social risk is defined for patients whose parents meet the following requirements: ${ }^{15}$

- Socio-economic level measured using poverty indicators.

- Mental retardation or psychiatric disorder.

- Substance abuse.

- History of battering or abandonment of other children.

- Minors who did not receive antenatal care.

- Other disabled minors in the household.

- Literacy problems.

Out of the patients seen jointly by the Follow-up Outpatient Clinic and the Department of Social Services, 32 were selected (10 female and 22 male patients) who were born between 32 and 36 weeks of gestational age and with a birth weight of 1500 $\mathrm{g}$ or more, and who had at least 2 of the socioenvironmental risk factors mentioned above.
Patients' age ranged between 8 and 24 months of adjusted age so that parents were able to have a more active interaction with them. Given their age, 2 started their participation as of the second workshop. Most patients had no evident developmental disorder although, at the clinic, they did not appear cooperative or sociable.

Coincidentally, they were assessed using the TADI; 22 had a normal total score (T) whereas 9 had a normal score with delay (at risk in the socioemotional skills area).

However, in general, scores in the socio-emotional skills and cognition areas were lower compared to the motor skills and language areas. In the latter area, 3 patients showed at risk scores. One of them was diagnosed with neurological "delay" and had a history of meningitis: this patient was included due to his/her social situation. All patients were accompanied by their mother; only 6 , by both parents; 12 were also accompanied by another family member (grandmother, aunt); and 7, by their siblings. Only 5 families participated as a whole. Mothers had a low level of education: $53.12 \%$ had completed primary education (many were functional illiterates); $6.2 \%$ were illiterate, and only $28 \%$ had completed secondary education, in addition to the fact that they were young. Also, $68.65 \%$ had attended 5 or more antenatal care visits; $6.25 \%$ had not received antenatal care and were adolescents. Besides, $78.12 \%$ were living with a couple, although they were in an unstable relationship because they had decided to live together once the female partner had become pregnant and had then separated. Likewise, fathers had a temporary job or lived on a pension or social assistance, and had no clear vision of their future (Table 1).

\section{ASSESSMENT TOOLS}

1. TADI. This test was created and validated in Chile, where the population is somewhat similar to that of Argentina. It is a very valuable, low-cost tool that can be administered by different health care providers. The TADI is used to assess children in the age range from 3 months and 1 day old to 6 years old. The areas under review include motor skills, language, cognition, and socioemotional skills, particularly; then an average is obtained for the four areas ( $\mathrm{T}$ score).

With these results, it is possible to assign children's performance into one of the development and learning categories: advanced, normal, at risk or delayed. If the 
total score is normal and a specific area is at risk/delayed, performance is categorized as "normal with delay." These are descriptive categories and account for a qualitative, not numerical, description. Patients taking part in the workshops were assessed in all areas before and after the project experience, whose results are reported in this article; subsequent assessments were conducted via the followup program.

2. Direct observation of bonding behavior. Parental commitment, accompanying the process of change, the extent of participation in workshops, bonding with their children during proposed activities, positive change in showing/expressing feelings towards their children.

3. Questionnaire developed by the team to be administered to the head of the family group. It was delivered to parents once the project experience finished. The questionnaire included a series of questions regarding the

TABLE 1. Demographic characteristics of participants. $N=32$. (Database of the Follow-up OutpatientClinic of Hospital Eva Perón de Tucumán)

\section{Maternal status}

1) Age

$\leq 18$ years old: 7

$>18-29$ years old: 18

$>30-39$ years old: 5

$\geq 40$ years old: 2

2) Number of antenatal care visits

$\geq 5: 22$

$\leq 4: 8$

None: 2

3) Level of maternal education Tertiary or university education: 0 Complete secondary education: 9 Incomplete secondary education: 2 Ongoing secondary education: 2

Complete primary education: 17 Illiterate: 2

4) Marital status Single: 7

Living with a couple: 23

Married: 2

\section{Paternal status}

Working (unstable job): 12

Unemployed: 2

Employed/trade: 13

Unknown: 5 workshops: choosing the more enjoyable workshop, the way it was delivered, its understandability and application at home, the experience itself, suggestions, and changes observed in their children and at home after attending the workshops. For a better interpretation, the score ranged from 0 to 10 and included a series of emoji for resignification of the answer (Annex 1).

\section{DEVELOPING THE EXPERIENCE: WORKSHOPS}

Five workshops were carried out between July and December 2015. Taking into consideration the distance from the place of residence and the traveling time, the workshops were conducted from $9 \mathrm{AM}$ to $12 \mathrm{PM}$, in a large, air-conditioned room adapted to the workshop theme.

Given that there was no specialized staff available to conduct the workshops, these were planned, implemented, and monitored by the team based on their personal experience and in accordance with the tools available for patients and their family groups. ${ }^{16}$ They were invited to a "games workshop" via a text message sent to their mobile phones from the Department of Referrals and Counter-Referrals of the hospital.

The work was carried out directly with the parents and indirectly with the children, using an experiential mode ${ }^{17}$ with multiple modules encompassing different thematic values and attempting to approach different theme areas planned pedagogically in a spiral manner. Themes were devised in response to the deficiencies observed by the team to enhance the development in all areas through the introduction or strengthening of these values, as follows (Annex 2):

- Workshop 1: Workshop introduction. The value of being a person. Children's rights.

- Workshop 2: Healthy eating (biologically and socially). The value of sharing and the community.

- Workshop 3: The value of family. Roles and responsibilities. Education and work culture.

- Workshop 4: The value of reading and storytelling.

- Workshop 5: The value of Christmas, regardless of creed (rebirth, union, forgiveness, peace).

Each workshop was guided alternatively by one of the departments involved. Team members were always the same, which facilitated family identification with the staff. Language and 
discourse were adapted, maintaining an adequate academic and health care level, to parental needs, inner strengths, and level of understanding, and considering that most were functionally or fully illiterate. ${ }^{18,19}$

Workshops started with theme introduction and followed with an activity — sometimes personaland ended with a group and community exchange of opinions. Easy-to-use and available tools were selected. The resources included two videos: "A story is not a joke," ${ }^{20}$ by Luis Landriscina, and "Storytelling from the sidelines," by José Luis Gallego, ${ }^{21}$ who coordinates workshops to develop and tell stories, which helps with the story creation and imagination process and promotes the formulation of a place for listening in vulnerable and marginal settings. The video describes the experience of a father who is in jail telling a story to his son. Once viewed, the videos were discussed and families were able to create their own story and put together a storybook for their children. In general, the workshop included handcrafting, role-playing, and a play, exposing personal situations and providing advice to family members. The final comprehensive task was conducted at a community level. They took home a significant material souvenir created in each event and committed to try and apply what they had experienced in the workshop..$^{22,23}$

\section{RESULTS}

All parents observed a positive change in their children's behavior following the workshops. They realized that they did not spend time playing with their children because they had not experienced it with their own parents. This way, they discovered activities unknown to them, their personal potential and ability to do things for their own and their children's benefit.

In the questionnaire, all parents scored the workshops with 9-10 (VERY GOOD), except for 2 who scored them 6-8: (1 in the "implementation at home of what you learned here" and 1 in the "have you noticed changes in your children's upbringing?" questions). Positive feedback was given under the "remarks" field (Table 2).

In the TADI, compared to the initial assessment, all participants improved their T score in the "normal" category (except for the patient with delay) and their scores in the socio-emotional skills and cognition areas, thus matching other areas. An improved attention and cooperation was also observed. Among the 3 participants at risk in the language area, 2 improved and the third one was referred for Speech Therapy; at present, this participant is delayed. No differences were observed in the number of participants of the family group or the type of socio-environmental risk (Table 3).

Children have been followed-up until the present time, and most of them are attending school on the initiative of their own family, wishing to improve more and more. T scores are still normal, with an adequate course, and children are now more sociable and willing to interact. Parents also evidence a positive change that has been maintained over time.

In relation to patient care, this holistic approach fostered an improved dynamics and meeting with other parents, which was an important milestone to recognize themselves in the other. From the perspective of learning, a permanent positive reinforcement was created, and parents became an integral part of their children's upbringing and

TABLE 2. Written feedback from participants assessing the workshops

- "The play was really nice; it taught me which household habits should be improved."

- "I liked everything, especially how my daughter managed the situation."

- "More mothers should bring their children to these workshops because you learn a lot here."

- "I liked them. I learned how to prepare the meals."

- "I would like to learn so that I can teach my children."

- "Thank you for everything; printing our hands was what I liked the most."

- "I liked the topic on feeding and children's rights."

- "I like all the workshops so far. I would like a workshop with puppets, and I would like to thank (...) because he was really helpful with my son."

"I like it because you learn a lot of things that are helpful for them."

- "I liked what I saw."

- "I liked the one on stimulating our children, sharing makes it safer."

- "I didn't know I would be able to tell a story to my son... My mom didn't have time and we would just go to school and back home and she never told us a story... It's a nice thing and I'm thrilled and excited." 
care. Although a lower level of compliance with appointments at the Follow-up Outpatient Clinic was observed, participants attended the "games workshop" even in spite of adverse weather conditions and resumed their usual follow-up visits. Participants also asked to continue with the workshops and suggested new topics.

\section{COMMENT}

Given the high demand, and for the sake of an improved care and interdisciplinary work, and also as proposed by parents themselves, a pilot test was planned and workshops for the promotion of child development were proposed between the Follow-up Outpatient Clinic and the Department of Social Services, with the

TABLE 3. Results of the Child Learning and Development Test (TADI) before and after the workshops

\begin{tabular}{|c|c|c|c|c|c|c|c|c|c|c|c|c|c|}
\hline \multirow[b]{2}{*}{ Patient } & \multirow[b]{2}{*}{ GA } & \multicolumn{5}{|c|}{ TADI 1} & \multicolumn{7}{|c|}{ TADI 2} \\
\hline & & Adj. & $\mathbf{T}$ & $\mathrm{C}$ & $\mathbf{M}$ & $\mathbf{L}$ & $\mathrm{SE}$ & Adj. & $\mathbf{T}$ & $\mathrm{C}$ & $\mathbf{M}$ & $\mathbf{L}$ & SE \\
\hline 1 & 36 & $8 \mathrm{~m}, 3 \mathrm{~d}$ & 47 & 41 & 57 & 47 & 43 & $14 \mathrm{~m}, 16 \mathrm{~d}$ & 50.5 & 49 & 60 & 47 & 46 \\
\hline 2 & 36 & $18 \mathrm{~m}, 10 \mathrm{~d}$ & 42.5 & 41 & 51 & 40 & 38 & $24 \mathrm{~m}, 13 \mathrm{~d}$ & 52.8 & 51 & 62 & 52 & 46 \\
\hline 3 & 36 & $8 \mathrm{~m}, 3 \mathrm{~d}$ & 42.25 & 41 & 48 & 40 & 40 & $14 \mathrm{~m}, 16 \mathrm{~d}$ & 46 & 45 & 50 & 47 & 42 \\
\hline 4 & 34 & $10 \mathrm{~m}, 8 \mathrm{~d}$ & 34 & 35 & 28 & 35 & 38 & $16 \mathrm{~m}, 16 \mathrm{~d}$ & 35.5 & 37 & 39 & 32 & 34 \\
\hline 5 & 35 & $18 \mathrm{~m}, 12 \mathrm{~d}$ & 40.4 & 41 & 48 & 35 & 38 & $23 \mathrm{~m}, 0 \mathrm{~d}$ & 46.5 & 48 & 55 & 40 & 43 \\
\hline 6 & 33 & $16 \mathrm{~m}, 1 \mathrm{~d}$ & 47 & 45 & 55 & 47 & 41 & $22 \mathrm{~m}, 16 \mathrm{~d}$ & 51 & 48 & 55 & 52 & 49 \\
\hline 7 & 36 & $8 \mathrm{~m}, 0 \mathrm{~d}$ & 50.5 & 49 & 55 & 52 & 46 & $14 \mathrm{~m}, 21 \mathrm{~d}$ & 52.5 & 53 & 55 & 52 & 50 \\
\hline 8 & 36 & $13 \mathrm{~m}, 14 \mathrm{~d}$ & 50.5 & 49 & 55 & 52 & 46 & $19 \mathrm{~m}, 3 \mathrm{~d}$ & 52.8 & 55 & 55 & 52 & 49 \\
\hline 9 & 35 & $14 \mathrm{~m}, 0 \mathrm{~d}$ & 50.5 & 49 & 55 & 52 & 46 & $30 \mathrm{~m}$ & 52.5 & 51 & 58 & 52 & 49 \\
\hline 10 & 35 & $23 \mathrm{~m}, 0 \mathrm{~d}$ & 50 & 44 & 62 & 48 & 46 & $28 \mathrm{~m}, 18 \mathrm{~d}$ & 56 & 48 & 65 & 57 & 54 \\
\hline 11 & 35 & $9 \mathrm{~m}, 1 \mathrm{~d}$ & 44.75 & 42 & 50 & 46 & 41 & $15 \mathrm{~m}, 4 \mathrm{~d}$ & 48 & 49 & 50 & 47 & 46 \\
\hline 12 & 32 & $9 \mathrm{~m}, 2 \mathrm{~d}$ & 47.25 & 42 & 53 & 46 & 41 & $15 \mathrm{~m}, 5 \mathrm{~d}$ & 51.5 & 49 & 60 & 47 & 50 \\
\hline 13 & 36 & $23 \mathrm{~m}, 1 \mathrm{~d}$ & 40.5 & 41 & 48 & 35 & 38 & $29 \mathrm{~m}, 0 \mathrm{~d}$ & 42.5 & 40 & 48 & 39 & 43 \\
\hline 14 & 36 & $16 \mathrm{~m}, 9 \mathrm{~d}$ & 44 & 45 & 43 & 47 & 41 & $22 \mathrm{~m}, 10 \mathrm{~d}$ & 53 & 51 & 55 & 52 & 54 \\
\hline 15 & 36 & $21 \mathrm{~m}, 15 \mathrm{~d}$ & 40.5 & 38 & 51 & 35 & 38 & $27 \mathrm{~m}, 15 \mathrm{~d}$ & 44 & 40 & 54 & 41 & 41 \\
\hline 16 & 36 & $21 \mathrm{~m}, 0 \mathrm{~d}$ & 48.25 & 44 & 58 & 48 & 43 & $27 \mathrm{~m}, 18 \mathrm{~d}$ & 53.3 & 53 & 58 & 52 & 50 \\
\hline 17 & 36 & $21 \mathrm{~m}, 15 \mathrm{~d}$ & 43.5 & 38 & 58 & 40 & 38 & $28 \mathrm{~m}, 16 \mathrm{~d}$ & 45 & 40 & 58 & 41 & 41 \\
\hline 18 & 36 & $13 \mathrm{~m}, 9 \mathrm{~d}$ & 42.75 & 41 & 50 & 41 & 39 & $20 \mathrm{~m}, 0 \mathrm{~d}$ & 46.3 & 44 & 55 & 43 & 43 \\
\hline 19 & 34 & $8 \mathrm{~m}, 19 \mathrm{~d}$ & 45.25 & 41 & 53 & 47 & 40 & $14 \mathrm{~m}, 23 \mathrm{~d}$ & 48.3 & 45 & 55 & 47 & 46 \\
\hline 20 & 34 & $8 \mathrm{~m}, 20 \mathrm{~d}$ & 43.75 & 41 & 53 & 43 & 38 & $14 \mathrm{~m}, 21 \mathrm{~d}$ & 48.3 & 45 & 55 & 47 & 46 \\
\hline 21 & 36 & $15 \mathrm{~m}, 24 \mathrm{~d}$ & 44.75 & 41 & 50 & 47 & 41 & $22 \mathrm{~m}, 28 \mathrm{~d}$ & 48.5 & 48 & 51 & 48 & 47 \\
\hline 22 & 34 & $18 \mathrm{~m}, 11 \mathrm{~d}$ & 48.25 & 44 & 58 & 48 & 43 & $25 \mathrm{~m}, 13 \mathrm{~d}$ & 53.3 & 53 & 58 & 52 & 50 \\
\hline 23 & 36 & $23 \mathrm{~m}, 24 \mathrm{~d}$ & 46.25 & 41 & 58 & 48 & 38 & $30 \mathrm{~m}, 14 \mathrm{~d}$ & 48.8 & 45 & 60 & 48 & 42 \\
\hline 24 & 35 & $8 \mathrm{~m}, 2 \mathrm{~d}$ & 43 & 41 & 48 & 43 & 40 & $15 \mathrm{~m}, 9 \mathrm{~d}$ & 46.3 & 45 & 50 & 44 & 46 \\
\hline 25 & 36 & $9 \mathrm{~m}, 0 \mathrm{~d}$ & 40.25 & 41 & 48 & 34 & 38 & $16 \mathrm{~m}, 0 \mathrm{~d}$ & 43.5 & 45 & 50 & 37 & 42 \\
\hline 26 & 34 & $8 \mathrm{~m}, 12 \mathrm{~d}$ & 40.25 & 41 & 42 & 40 & 38 & $11 \mathrm{~m}, 22 \mathrm{~d}$ & 47 & 49 & 50 & 46 & 43 \\
\hline 27 & 34 & $8 \mathrm{~m}, 13 \mathrm{~d}$ & 40.75 & 41 & 42 & 40 & 40 & $11 \mathrm{~m}, 16 \mathrm{~d}$ & 48 & 49 & 50 & 47 & 46 \\
\hline 28 & 36 & $17 \mathrm{~m}, 20 \mathrm{~d}$ & 47.25 & 45 & 55 & 47 & 42 & $24 \mathrm{~m}, 18 \mathrm{~d}$ & 55 & 51 & 58 & 57 & 54 \\
\hline 29 & 36 & $12 \mathrm{~m}, 11 \mathrm{~d}$ & 47 & 45 & 55 & 47 & 41 & $19 \mathrm{~m}, 12 \mathrm{~d}$ & 51.5 & 51 & 58 & 48 & 49 \\
\hline 30 & 36 & $14 \mathrm{~m}, 6 \mathrm{~d}$ & 47.25 & 45 & 55 & 47 & 42 & $21 \mathrm{~m}, 1 \mathrm{~d}$ & 52.5 & 51 & 58 & 52 & 49 \\
\hline 31 & 35 & $19 \mathrm{~m}, 0 \mathrm{~d}$ & 46.25 & 44 & 55 & 43 & 43 & $23 \mathrm{~m}, 25 \mathrm{~d}$ & 51 & 51 & 58 & 48 & 47 \\
\hline 32 & 36 & $11 \mathrm{~m}, 15 \mathrm{~d}$ & 47 & 45 & 55 & 47 & 41 & $17 \mathrm{~m}, 12 \mathrm{~d}$ & 51.8 & 51 & 55 & 52 & 49 \\
\hline
\end{tabular}

Categories for the interpretation of $\mathrm{T}$ scores

\begin{tabular}{lll} 
T score & Category & Remark \\
\hline 60 or more & Advanced & \\
$40-59$ & Normal & Normal total score with an area that showed at risk or delay: normal with delay \\
$30-39$ & At risk & \\
29 or less & Delayed & \\
\hline
\end{tabular}

References:

Adj.: adjusted age; GA: gestational age; m: months (e.g., 9 m); d: days (e.g., 9 d); T: total score; C: cognition; M: motor skills; L: language; SE: socio-emotional skills. 
collaboration of the Department of Nutrition. It was a "challenge" because it meant intervening in human aspects, for the purpose of an auspicious modification. In addition, compared to other successful experiences carried out in other countries, this was an unprecedented proposal in our setting in terms of patients' age (younger than 2 years) and given the lack of a specific program. The problem was approached by working directly with parents and indirectly with their children. This enabled getting to know and recognizing the internal culture of these families.

As a health care team, it was possible to deepen interpersonal and professional relations, and team members' abilities -mostly unknown- were improved and developed even more.

Regardless of the type of socio-environmental risk, the importance of an early intervention in a critical period of development was confirmed. An early intervention and detection favored the overall development of these children who, throughout their lives, have greater needs beyond what is merely biological, and were carried out through an holistic approach ${ }^{24,25}$ from social, educational, and psychological views; besides, all these needs affect the family group: an intervention aimed at parents may favor the development of cognition and socioemotional skills.

In the field of Health Management, it is not easy to demonstrate -and highlight- the importance of attending the Follow-up Outpatient Clinic and the conduction of early interventions. In spite of taking place at a small scale, this experience helped to demonstrate that, in our setting, as in other European countries, Brazil or the United States, ${ }^{26}$ it was possible to carry out a program to favor an adequate upbringing based on strengthening family bonding, and capable of changing inadequate and unfavorable behaviors, for the future of these children's socio-environmental development adapted to a healthier and more equal society, also from aneconomic perspective. This encouraged the team to implement the project in a systematic manner over time to the entire population of the East Programmatic Area, currently under planning.

The direct manner to do so is working together as a team, demonstrating the potential of children since the moment they are admitted to the program. The project aims at helping parents to get a new, different perspective about everything related to their children's upbringing and to leave the experiential workshops convinced that they are capable of doing so through the demonstration of newborn infant care guidelines, the promotion of education, even for themselves, and the facilitation and encouragement of a work culture by teaching them that they could build a new, warm, and high-quality life based on their own tools. Ultimately, to achieve the long overdue human advancement in terms of equity and equality for the purpose of a joint, healthy, and sustainable society, at a personal and social level.

\section{REFERENCES}

1. Young M. Justificación de la intervención temprana. En: Desarrollo del niño en la primera infancia: una inversión en el futuro.Washington, DC: Banco Mundial; 2010.

2. Di Iorio S, Rodrigo M, Urrutia M. Desarrollo psicológico, nutrición y pobreza. Arch Argent Pediatr 1998;96(4):219-19.

3. Luby J, Belden A, Bolteron K, et al. The Effects of Poverty on Childhood Brain Development: The Mediating Effect of Caregiving and Stressful Life Events. JAMA Pediatr 2013;167(12):135-42.

4. Piaget J. La Psicología de la Inteligencia. Buenos Aires: Psique, 1973.

5. Piaget J.Seis estudios de psicología. Barcelona: Ariel, 1986.

6. PiagetJ. El nacimiento dela inteligencia en el niño. Madrid: Aguilar, 1972.

7. Edwards M, Pardo M. Test de Aprendizaje y Desarrollo Infantil TADI. Centro de Estudios de Desarrollo y Estimulación Psicosocial CEDEP. Universidad de Chile, 2013. [Accessed on: May 12 ${ }^{\text {th }}, 2012$ ]. Available at: https: / / tadi.cl/.

8. Schapira I, Toledo S, Roy E, et al. Los años formativos. Desarrollo e intervención oportuna en los primeros cinco años de vida. Buenos Aires: Fundación Neonatológica para el recién nacido y su familia, 2010.

9. Larguía M, Schapira I, Aspres N, et al. Guía para padres de prematuros. Buenos Aires: Fundación Neonatológica para el recién nacido y su familia, 2008.

10. Oiberman A, Mercado M. Nacer, jugar y pensar: guía para acompañar a los bebés desde su gestación hasta los tres años. Buenos Aires: Lugar, 2007.

11. Hermida MJ, Segretin MS, Lipina SJ, et al. Abordajes neurocognitivos en el estudio de la pobreza infantil: consideraciones conceptuales y metodológicas. Intern Jour Psych Psychol Therapy 2010;10(2):205-25.

12. Ministerio de Salud de la Nación-OPS. Indicadores básicos de Salud. Argentina 2011. Esperanza de vida Tucumán y Argentina. [Accessed on: May 12 ${ }^{\text {th }}$, 2012]. Available at: http: / / publicaciones.ops.org.ar/publicaciones / indicadores/indicadores-nacion-2011.pdf.

13. Ministerio de Salud Pública de Tucumán. Documento de medición y monitoreo de indicadores de las metas de recursos humanos para la salud en la provincia de Tucumán. [Accessed on: May 17th, 2017]. Available at:http: / / www.msal.gob.ar/observatorio/images/stories / documentos_red_federal/observatorios-provinciales / Tucuman/InformeTM-Tucuman-Dic2014.

14. UNICEF-Sociedad Argentina de Pediatría. Salud maternoinfantil-juvenil en Cifras. 2015. [Accessed on: May $12^{\text {th }}$, 2017]. Available at: https: / / www.unicef.org/argentina / spanish/SALUD_Sap-Unicef_2015_web.pdf.

15. Peralta MI, Muñoz C. La situación del trabajo infantil y su relación con las políticas públicas e intervención social en 
Argentina y Chile. Perspectivas 2006;17:75-122.

16. Vygotsky L. Pensamiento y lenguaje. Barcelona: Paidós Ibércia, 2010.

17. Dewey J. Experiencia y Educación. Madrid: Biblioteca Nueva, 2004

18. Freire P.Pedagogía del oprimido. Buenos Aires: Siglo XXI, 1996.

19. Freire P. Pedagogía de la autonomía: saberes necesarios para la práctica educativa. 2da ed. Buenos Aires: Siglo XXI, 2008.

20. Landriscina L. El cuento no es chiste. [Accessed on: May 12 $\left.{ }^{\text {th }}, 2017\right]$. Available at: https://www.youtube.com/ watch?v=Ul_9ggGa6vA.

21. Gallego JL. Conferencia TEDx "Contando desde los márgenes". La Plata Argentina, 2013. [Accessed on: May 12 ${ }^{\text {th }}$ 2017]. Available at: https://www.youtube.com/ watch?v=L-eSrNZsZIE.
22. Sameroff AJ, Fiese BH. Transactional regulation: the developmental ecology of early intervention. In: Shonkoff JP, MeiselsSJ (eds.). Handbook of early childhood intervention. 2nd ed. New York: Cambridge University Press, 2000. Pages 135-59.

23. Morasso MC, Duro E (Coord). Nutrición, Desarrollo y Alfabetización: una propuesta integradora en favor de la infancia. 2.da ed. Buenos Aires: UNICEF, 2004. [Accessed on:May $12^{\text {th }}$, 2017]. Available at:https: / / www.unicef.org/ argentina/spanish/ar_insumos_NAD1.pdf.

24. BronfenbrennerU,CeciSJ.Nature-nurturereconceptualized: A bioecological model. Psychol Rev 1994;101(4):568-86.

25. Bronfenbrenner U. La Ecología del Desarrollo Humano. Barcelona: Paidós Ibérica, 1987.

26. Oates J. Apoyo a Los Padres. Aberystwyth: The Open University, 2010. 


\section{ANNEX 1 \\ QUESTIONNAIRE FOR PARENTS FOLLOWING THE WORKSHOPS}

WORKSHOP ON CHILD REARING PRACTICES

* Mark with an $\mathrm{X}$ the most adequate emoji.

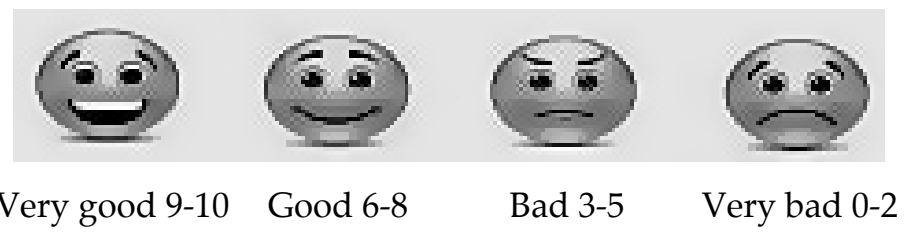

\section{QUESTIONNAIRE}

How did you feel during the workshop?

Did you enjoy the topicsdiscussed during the workshop?

Do you think the workshop will help you raise your child more comfortably?

Did you like how the workshop was given?

Were you able to implement it at home?

Have you noticed changes in your children's upbringing?

Which workshop did you like the most?

1. Making a rattle. Children's rights.

2. Feeding. Fruit salad.

3. Play. The family.

4. Making a storybook. Reading and storytelling.

5. Christmas. Decorating a Christmas tree.

Have you ever experienced a similar learning process? YES NO

Would you like to discuss other topics?.

Suggestions:

First and last name: 


\section{ANNEX 2 \\ WORKSHOP PLANNING}

WORKSHOP 1: Workshop introduction. The value of oneself (being a person)

- Objective:

1) Workshop introduction and getting to know children's rights.

2) Making a home-made toy (a rattle or similar toy).

- Goal: To make parents aware of the value of being oneself through the discovery of their own artistic and individual skills.

- Activities:

1) Inductive talk given by the Department of Social Services.

2) Exchange of ideas.

3) Making a rattle.

- Materials:

1) PowerPoint presentation.

2) Disposable $500 \mathrm{ml}$ bottle, egg-based paints, paint brushes, glitter, sequins, noodles, water, paper of different colors, EVA rubber, scissors, glue, adhesive tape.

WORKSHOP 2: Healthy eating. The value of sharing and the community.

- Objective: To create awareness about the importance of eating for the biological development and as a social event.

- Goal: To improve the quality of meals by sharing the parents' experiences and improving "social eating."

- Activities:

1) Each family makes a drawing of a meal they usually cook.

2) All meals and ingredients are shown, and remarks and guidance are provided on how to improve them.

3) Parents discuss their experiences and constructive opinions are given on healthy eating.

4) Talk about healthy eating.

5) Making a "community" fruit salad with the help of parents and their children.

6) Sharing the fruit salad with every participant.

- Materials:

1) A poster board with the printed drawing of a plate and cutlery.

2) Magazines to cut out pictures of fruits, vegetables, and healthy seasonings.

3) Prints of healthy foods and their classification.

4) Fruits in season, large salad bowl, knives, plates, napkins, glasses, spoons.

WORKSHOP 3: The value of family (play).

- Objective: To show The value of family.

- Goal: To recognize the family as the first basic community, where roles, respect, responsibility, sharing, and upbringing in general are represented.

- Activities:

1) Play with the participation of members from the different departments involved. Theme: A dysfunctional family at lunchtime.

2) Working in groups and discussing what participants saw and what would be more adequate for a better family functioning.

3) Role playing with the participants about which values improve families as such. 
- Materials: Write a script about antisocial behavior in the setting of a dysfunctional family at lunchtime. Stage and supporting actors played by the members of the three collaborating departments (Follow-up Outpatient Clinic, Department of Social Services, Department of Nutrition).

\section{WORKSHOP 4: The value of reading and storytelling.}

- Objective: To introduce reading as a means for language development, communication, attention, cognition, imagination, and exchange between parents and children, and improve their bonding.

- Goal:

1) To make parents capable of telling stories that they can share with their children and discover their own potential and the positive influence they could have on their children.

2) Discovering storytelling and its power. Imagination and devising. Working with attention and collaboration.

- Activities:

1) Inductive talk and video on the importance of reading and stories.

2) Telling a story orally together with parents guided by the members of the Follow-up Outpatient Clinic.

3) Introducing dentistry into stories through the presentation of "Mr. Tooth" and ending the story.

4) Making a storybook.

- Materials:

1) TEDx Talk videos (stories in jail) and Landriscina video (an everyday story).

2) Mr. Tooth costume.

3) Corrugated cardboard, poster boards, egg-based paints, paint brushes, pencils, plush, magazines, scissors, glue, adhesive tape, wool of different colors, coloring prints.

\section{WORKSHOP 5: The value of Christmas regardless of creed}

- Objective: To describe Christmas as union, sharing, forgiveness, and peace.

- Goal: To use Christmas as a timely moment of the year to restart in the best way possible, regardless of creed, and not just as a commercial or calendar event.

- Activities:

1) Inductive talk given by the three departments involved.

2) Exchange of ideas and experiences.

3) Decorating a small Christmas tree to be placed on the table at home.

4) Decorating a "community" Christmas tree with balls printed with the hands of all participants (parents, children, staff).

5) Giving a toy to each participant.

6) Placing the community Christmas tree in the hospital hall as a peace offering for the community as a whole. 